\title{
Peningkatan Hasil Belajar Fisika Melalui Penerapan Media Pembelajaran E-Learning Berbasis Schoology: Studi Kasus di SMAN 1 Karangdowo.
}

\author{
${ }^{1}$ Toto Sugiarto \\ ${ }^{1}$ Sekolah Menengah Aatas Negeri 1 Karangdowo Klaten, Jawa Tengah \\ Email Korespondensi: totouaninha@gmail.com
}

\begin{tabular}{|c|c|}
\hline \multicolumn{2}{|l|}{ Article Info } \\
\hline \multicolumn{2}{|c|}{ Article History } \\
\hline \multicolumn{2}{|c|}{ Received: 19 February } \\
\hline \multicolumn{2}{|c|}{ Revised: 21 March 2020} \\
\hline \multicolumn{2}{|c|}{ Published: 25 March 2020} \\
\hline \multicolumn{2}{|l|}{ Keywords } \\
\hline $\begin{array}{l}\text { E-Learning } \\
\text { physics, }\end{array}$ & $\begin{array}{r}\text { Schoology, } \\
\text { learning }\end{array}$ \\
\hline
\end{tabular}

Informasi Artikel

Sejarah Artikel

Diterima: 19 Februari 2020

Direvisi: 21 Maret 2020

Dipublikasi: 25 Maret 2020

Kata kunci

Pembelajaran, E-Learning Scholoogy, Fisika,

\begin{abstract}
The purpose of this research was to find out the Influence of E-Learning with Schoology on physics learning. The success indicators in this study is cosidered when at least $75 \%$ of students were able to passed the required standard minimum score. The reseach aims to evaluate the effectiveness of E-Learning Schoology to increase the level of understanding in learning physics at Karangdowo 1 Senior Highschool (SMAN 1 Karangdowo). The research was built upon the classroom observation to 35 students from the class of XI IPS 4. The research will begin on July 16 until August 20, 2019. The duplicated data containing three meeting on each cycle were recodered at two observational points: pre-and post-application cycles of the learning strategy. The students learning ability meassured by pre-cycle posttest was estabished as an initial baseline., following by recorded the improvement of the latter after the ELearning Schoology has been applied. The result have shown that students understanding level in learning pysics is increased by $10.71 \%$ depicted by the increasing number of students (in percentage) that passed the standard minimum grade 70 , on pre-cycle (25.7\%) compared with the post-cyle (51.4 and $85.71 \%$ ). The latter two scores were obtained from the post cycle-posttest scores after the application of the basic E-Learning Schoology and its associated modification method, respectively.Therefore, it can be concluded that the E-Learning Schoology can be considered as a promising method to increase learning outcomes for senior high school students in learning physics.
\end{abstract}

\section{Abstrak}

Tujuan dari penelitian ini adalah untuk mengetahui Pengaruh E-Learning dengan Schoology pada pembelajaran fisika. Indikator keberhasilan pada penelitian ini adalah 75\% nilai siswa tuntas KKM. Penelitian Tindakan Kelas yang dilaksanakan di SMAN 1 Karangdowo tepatnya di kelas XI IPS-4 yang berjumlah 35 siswa. Pelaksanaan penelitian dimulai tanggal 16 Juli sampai 20 Agustus 2019. Penelitian ini dilaksanakan dalam dua siklus, tiap siklus terdiri dari tiga kali pertemuan. Teknik pengambilan data dilakukan dengan test, observasi, dan dokumentasi. Observasi sebelum tindakan penelitian yaitu berupa pemberian pre-test prasiklus. Pada pre-test prasiklus hanya sebesar 25,7\% siswa yang memiliki nilai diatas KKM, dengan nilai KKM 70. Pada siklus I mulai diberi tindakan dengan strategi pembelajaran Schoology pada proses pembelajaran, pada siklus I ini nilai posttest siswa meningkat menjadi 51,4\% siswa yang tuntas KKM. Pada siklus II dilanjutkan menggunakan metode yang sama, yaitu strategi pembelajaran Schoology yang telah dilakukan sedikit modifikasi yaitu dengan menambah jumlah kelompok dari 6 menjadi 8 kelompok, dan anggota kelompok dipilih oleh guru. Pada siklus II, nilai posttest siswa meningkat menjadi 85,71\% yang memiliki nilai diatas KKM. Berdasarkan hasil posttest siklus II dapat dikatakan bahwa penelitian menggunakan strategi pembelajaran Schoology ini telah berhasil dengan peningkatan hasil belajar 10,71\%. Saran peneliti untuk penelitian yang lebih baik lagi jika pasilitas internet yang memadai sehingga akses ke Schoology lebih cepat. 
Sitasi: Sugiarto, Totok. (2020). Peningkatan Hasil Belajar Fisika Melalui Penerapan Media Pembelajaran ELearning Berbasis Schoology: Studi Kasus di SMAN 1 Karangdowo. 2(1) 43-51.

\section{PENDAHULUAN}

Pemanfaatan teknologi informasi dan komunikasi untuk pendidikan bisa dilaksanakan dalam berbagai bentuk sesuai fungsi dan kegunaannya dalam pendidikan. Schoology adalah platform media sosial yang digunakan untuk pembelajaran dan berfungsi untuk berbagi ide, file, agenda kegiatan dan penugasan guna menciptakan interaksi yang dinamis antara guru dan siswa (Murthosyiya, 2017). Pelajaran fisika sangat penting untuk dikuasai siswa, sebab ketika siswa menguasai materi mereka dapat menerapkannya dalam kehidupan sehari-hari (Septiani dan Indri, 2019).

Peneliti selaku guru fisika di SMA Negeri 1 Karangdowo menemukan beberapa permasalahan dalam pembelajaran di kelas. Siswa kurang berminat belajar fisika, ketika diterangkan ada beberapa yang ngantuk, tidak pernah mencatat dengan alasan tidak jelas ketika diterangkan guru. Hasil pre-test hanya $25,7 \%$ siswa yang tuntas, sehingga pencapaian hasil belajar fisika juga rendah. Peneliti tertarik menggunakan pembelajaran berbasis E-Learning Schoology untuk meningkatkan hasil belajar fisika. Penggunaan E-Learning dengan Schoology dalam pembelajaran fisika dapat membantu siswa dalam menyelesaikan kesulitan memahami konsep fisika yang bersifat abstrak, dengan memberikan pengalaman yang lebih konkret dan membantu dalam mengarahkan imajinasi siswa. dan sebagai solusi dalam pembelajaran yang lebih dinamis dan interaktif (Utami et al., 2017).

Penggunaan model pembelajaran E-Learning Schoology dalam proses pembelajaran membuat siswa lebih cepat mengerti dalam proses pembelajaran, karena siswa mendapat pengalaman baru dalam proses belajar serta menumbuhkan rasa kepercayaan diri (self-efficacy) siswa (Manfaat yang didapat dengan pembelajaran menggunakan media E-Learning adalah pembelajaran lebih realistis dan kontekstual (Rijal, 2017). Pembelajaran dengan E-Learning dapat membimbing peserta didik untuk belajar secara mandiri sehingga pembelajaran dapat beralih dari pembelajaran yang berorientasi pada guru (teacher centered), menjadi pembelajaran yang berorientasi pada peserta didik (student centered) (Hernani et al., 2019). ELearning merupakan model pembelajaran yang dirancang dengan tujuan menggunakan sistem elektronik atau komputer sehingga mampu meningkatkan proses pembelajaran (Michael, 2013).

Guru memiliki tanggung jawab untuk mendidik manusia yang unggul, dan menjadi ujung tombak penentu kualitas hasil pendidikan. Guru dituntut untuk lebih kreatif dalam menentukan strategi pembelajarannya (Khafid dan Mohammad Abdul, 2019). The quality of human resources that has competitiveness is defined by the education system. Teacher is the spearhead in determining the quality of education outcomes in Indonesia (Safriana, 2019). Schoology dapat melakukan pengaturan/moderasi terhadap pengguna/ user yang ingin bergabung pada group/kelas, pada status access group sebagai invite only, allow requests ataupun open. Adanya aplikasi absensi sebagai fitur pelengkap E-Learning Schoology memudahkan guru melihat keikutsertaan siswa dalam proses pembelajaran yang dilakukan di dunia maya (Wati dan Asnita, 2016).

Menurut Rahmadianto (2017) menyatakan bahwa pemanfaatan Schoology sebagai media pembelajaran bisa meningkatkan hasil belajar siswa dibandingkan penggunaan media pembelajaran konvesional. Penerapan E-Learning dengan media Schoology dapat dijadikan alternatif bagi guru dalam malakukan pembelajaran baik dikelas maupun diluar kelas, karena Schoology dapat digunakan dimanapun dan kapanpun atau tidak ada batasan waktu 
penggunaannya (Ulva at al., 2017). Guru diharapkan menggunakan pembelajaran berbasis Schoology agar dapat mengasah pola pikir peserta didik untuk berfikir secara kreatif dan kritis (Fidiatun at al., 2018). Melihat latar belakang yang dipaparkan di atas, maka peneliti memutuskan untuk memfokuskan pemecahan masalah yang dihadapi dengan menggunakan media pembelajaran Schoology. Pembelajaran yang digunakan oleh guru diharapkan siswa akan lebih giat lagi dalam belajar. Hasil belajar juga diharapakan menjadi lebih baik lagi dari sebelumnya.

\section{METODE}

Metode penelitian yang digunakan adalah Penelitian Tindakan Kelas (PTK), ada empat langkah dalam PTK yaitu perencanaan, tindakan, observasi dan refleksi. Subyek penelitian ini adalah siswa SMAN 1 Karangdowo kelas XI IPS4 (lintas peminatan) berjumlah 35 siswa. Penelitian ini dilakukan di SMAN 1 Karangdowo, di kelas XI IPS4. Waktu penelitian adalah bulan Juli hingga Agustus 2019. Proses pembelajaran yang sudah disusun, kemudian diadakan suatu observasi dan evaluasi yang digunakan sebagai masukan untuk melakukan refleksi atas apa yang terjadi pada tahap pelaksanaan. Hasil dari proses refleksi kemudian diadakan perbaikan dan penyempurnaan rencana tindakan berikutnya (Adelia, 2014). Adapun siklus dalam penelitian dapat digambarkan seperti berikut ini:

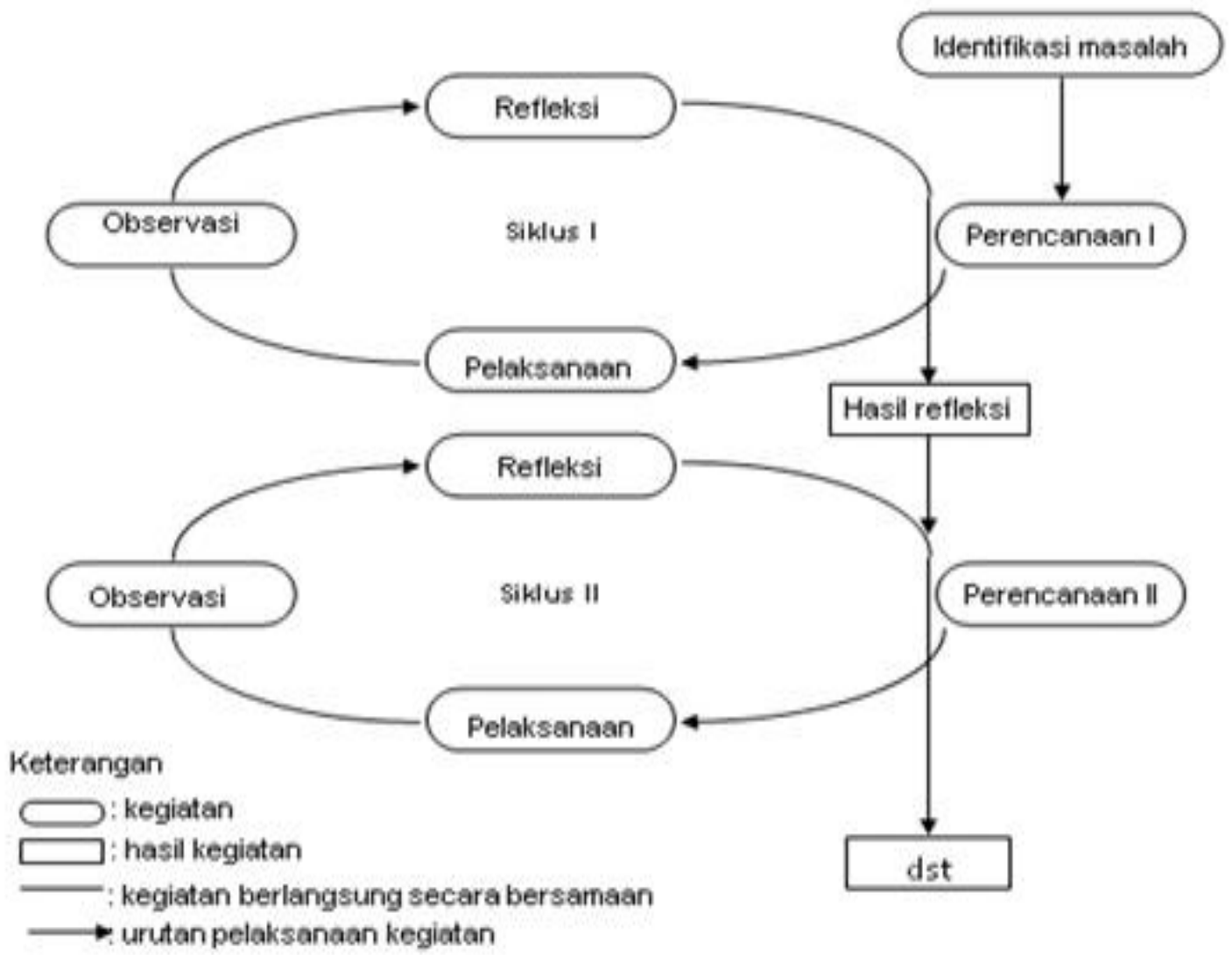

Bagan I. Tahapan PTK (Kemmis dan Taggart dalam Arikunto, 2013:132) 
Langkah-langkah tiap siklus

1. Siklus I

a. Perencanaan I (Plan)

Peneliti melakukan refleksi awal, kemudian melakukan analisis kurikulum guna menentukan kompetensi dasar yang akan disampaikan kepada siswa dengan menggunakan model pembelajaran Schoology. Dalam tahap perencanaan, peneliti menyiapkan:

1) RPP menggunakan strategi pembelajaran Schoology.

2) Modul materi online yang digunakan untuk pelaksanaan strategi pembelajaran Schoology.

3) Membuat lembar observasi yang akan diisi oleh observer.

4) Membuat 10 soal pilihan ganda berkaitan dengan materi yang dijelaskan untuk post test.

b. Pelaksanaan I (Action)

Tindakan dilakukan dengan menggunakan panduan perencanaan baik online ataupun off line yang bersifat terbuka dan fleksibel dalam pelaksanaannya.. Dalam pembelajaran guru berpedoman pada RPP berbasis Schoology. Observer melakukan kegiatan pengamatan selama proses pembelajaran. Proses pembelajaran dilakukan dalam tiga tahap yaitu kegiatan awal, kegiatan inti, dan kegiatan akhir.

1) Kegiatan Awal

Kegiatan awal dilakukan dengan:

a) Mengucapkan salam kemudian berdoa

b) Mengabsen siswa

c) Memberikan pertanyaan yang berkaitan dengan materi yang akan disampaikan guna memotivasi siswa

d) Menginformasikan tujuan pembelajaran yang akan dicapai

2) Kegiatan Inti

a) Guru menginformasikan materi yang akan dipelajari

b) Guru membuat kelompok belajar siswa

c) Guru menginformasikan materi yang sudah di upload di Schoology untuk diskusi kelompok

d) Guru menjelaskan cara belajar dengan Schoology

e) Siswa berdiskusi tentang materi yang diberikan secara online

f) Guru meminta siswa mengakses materi keseimbangan di courses/ kelas online pada fitur Schoology

g) Guru memberikan penjelasan dan pembenaran jawaban hasil diskusi di grup Schoology

h) Guru memberikan kesempatan tanya jawab dengan siswa

3) Kegiatan Akhir

a) Guru menyampaikan rencana pembelajaran pada pertemuan berikutnya

b) Guru memberikan posttest kepada siswa

c) Guru menutup kegiatan pembelajaran

c. Observasi I (Observation)

Observasi dilakukan saat KBM, observer melakukan pengamatan saat pembelajaran berlangsung, mengamati kegiatan secara teliti kemudian mencatat permasalahan yang ada sebagai bahan diskusi dengan peneliti yang digunakan untuk merefleksi kegiatan pembelajaran. 


\section{d. Refleksi I (Reflection)}

Refleksi dilakukan untuk merumuskan tindakan perbaikan pada siklus berikutnya. Observer berkolaborasi dengan peneliti guna menyusun rencana tindakan untuk Siklus II, jika rancangan pada Siklus I belum dapat memenuhi target yang dapat diharapkan.

2. Siklus II

Siklus II dilakukan seperti pada pembelajaran di siklus I yang meliputi kegiatan perencanaan, kegiatan inti, kegiatan pengamatan dan refleksi.

a. Perencanaan II (Plan)

Peneliti melakukan persiapan untuk memperbaiki refleksi siklus I,berdasarkan informasi dari refleksi siklus I. Refleksi siklus I merupakan data yang digunakan untuk membuat perencanaan siklus II. Hal yang dipersiapkan di dalam siklus II adalah Rencana Pelaksanaan Pembelajaran (RPP).

b. Pelaksanaan II (Action)

Seperti pada tahap pelaksanaan siklus I, pada siklus II guru menyampaikan kembali tujuan, garis besar materi, menjelaskan langkah-langkah strategi pembelajaran Schoology, dan mengupload materi keseimbangan dan soal secara online di Schoology . Selain itu guru membimbing siswa dalam pembelajaran.

c. Observasi II (Observation)

Sama seperti siklus I, observer harus mengamati aktivitas strategi pembelajaran Schoology, apakah pembelajaran sudah sesuai dengan skenario atau belum.

d. Refleksi II (Reflection)

Peneliti melakukan refleksi terhadap pelaksanaan siklus kedua. Dalam tahap refleksi siklus II ini, peneliti merekap lembar observasi. Jika tujuan pembelajaran mengalami peningkatan yang signifikan maka penelitian dianggap berhasil.

\section{HASIL DAN PEMBAHASAN}

Nilai KKM ranah kognitif pelajaran fisika kelas XI IPS4 (lintas peminatan) SMAN 1 Karangdowo Kabupaten Klaten adalah 70. Berdasarkan nilai ranah kognitif hasil pre- test siswa prasiklus dapat diketahui bahwa sebanyak 26 siswa mendapatkan nilai dibawah KKM, hal ini berarti hanya $25,7 \%$ yang memiliki nilai diatas 70 atau diatas KKM pada mata pelajaran fisika. Kegiatan pembelajaran dimulai dengan guru meminta siswa membentuk kelompok menjadi 6 kelompok. Guru menjelaskan cara menggunakan fitur-fitur pembelajaran yang ada di Schoology, kemudian siswa diminta mengaktifkan hp atau laptopnya untuk mengakses Schoology dan bergabung dengan grup kelas yang sudah dibuat guru. Siswa bergabung ke ruang kelas online Schoology dan mengakses materi keseimbangan benda tegar dalam bentuk blog kemudian berdiskusi tentang materi keseimbangan yang telah diberikan oleh guru. Guru menganalisis materi yang sudah diupload di Schoology dan meminta siswa mengajukan pertanyaan terhadap materi yang tidak mereka pahami. Siswa dapat melakukan share materi sesama mereka, atau share bersama guru.

Siklus I mulai dilaksanakan pada 16 Juli 2019. Kegiatan pembelajaran dimulai dengan guru meminta siswa mengakses materi di Schoology dan membuka fitur-fiturnya. Pembelajaran dilakukan dengan Schoology, kemudian mendiskusikan materi keseimbangan benda tegar, siswa dibagi menjadi 6 kelompok. Pengelompokan siswa ditentukan oleh siswa sendiri, masing-masing kelompok diberi tugas untuk mengakses materi fisika tentang keseimbangan benda tegar di blog Schoology. Pada siklus I dilakukan posttest 1 dimana siswa 
diberi 10 soal pilihan ganda. Berdasarkan posttest 1 yang dilakukan siswa, dapat disimpulkan bahwa hanya 51,4\% siswa dari 35 siswa yang memiliki nilai diatas KKM, sedangkan sebanyak 17 siswa memiliki nilai dibawah KKM. Refleksi awal pada penelitian tindakan kelas secara $E$ Learning Schoology peneliti mendapati ada beberapa kekurangan yang harus diperbaiki. Misalnya pada penetapan waktu yang diberikan kepada siswa, semula hanya memberikan intruksi yang akan keluar lewat notifikasi HP masing-masing siswa tanpa memberikan batasan waktu untuk satu konsep materi. Hal ini mengakibatkan siswa lalai untuk membuka kotak diskusi. Untuk latihan soal, waktu yang diberikan terlalu lama tanpa time limit. Hal ini memicu siswa untuk melakukan kerjasama dan negosiasi diantara sesama mereka. Hasil refleksi pertama ini di gunakan untuk perbaikan pada proses pembelajaran E-Learning berikutya. Peneliti mulai dengan memberikan batasan waktu untuk setiap fitur yang akan dilaksanakan, siswa mengikuti dengan disiplin dan seksama. Semua refleksi yang diperoleh pada tahap awal digunakan untuk perbaikan pada tahap berikutnya. Berdasarkan presentase ketuntasan tersebut, dapat dikatakan bahwa pencapaian tersebut masih berada dibawah indikator keberhasilan. Sehingga penelitian tindakan kelas ini dilanjutkan ke siklus berikutnya.

Siklus II dimulai pada tanggal 6 Agustus 2019. Proses pembelajaran pada siklus II kurang lebih sama dengan siklus I, namun peneliti melakukan beberapa hal yang berdasarkan saran dari observer, yaitu anggota kelompok terlalu banyak dan sebaiknya hasil diskusi ditampilkan di layar LCD dan dishare di Schoology.. Kegiatan pembelajaran dimulai dengan guru meminta siswa menjadi 8 kelompok, pengelompokan siswa ditentukan oleh guru, hal ini dilakukan agar siswa tidak memilih-milih teman kelompoknya dan kemampuan anggota merata, hal ini sesuai dengan saran observer pada siklus I. Siswa dalam siklus II ini juga sudah mulai menunjukkan ketertarikkannya dalam pembelajaran dengan menggunakan Schoology. Hal ini dapat dilihat banyaknya siswa yang sudah mau bertanya dan aktif dalam pembelajaran. Berdasarkan hasil posttest 2 pada siklus II maka dapat dilihat bahwa 30 siswa telah tuntas KKM dengan rata-rata nilai 80,57 dengan presentase ketuntasan siswa 85,71 \%, maka siklus II dikatan berhasil karena telah melewati batas indikator ketuntasan. Sehingga penelitian tindakan kelas ini dapat dihentikan. Hasil yang diperoleh dalam penelitian ini diperkuat oleh hasil peneliti terdahulu yang mengungkapkan bahwa dalam proses pembelajaran yang sedang berlangsung sudah berhasil, jika ketuntasan hasil belajar peserta didik sudah melebihi indikator yang diharpakan (Fidiatun at al., 2018). Siswa yang belajar dengan menggunakan media pembelajaran E-Learning Schoology memperoleh hasil secara signifikan, hasil belajar dengan menggunakan Schoology lebih baik daripada yang menggunakan media pembelajaran konvensional (Kusumantara at al., 2017). Pembelajaran menggunakan blended learning (ELearning Schoology dan tatap muka) dapat meningkatkan hasil belajar pada ranah kognitif level higher order thinking skill siswa (Azizah, 2017).

Grafik dibawah ini adalah hasil peningkatan nilai belajar siswa. 


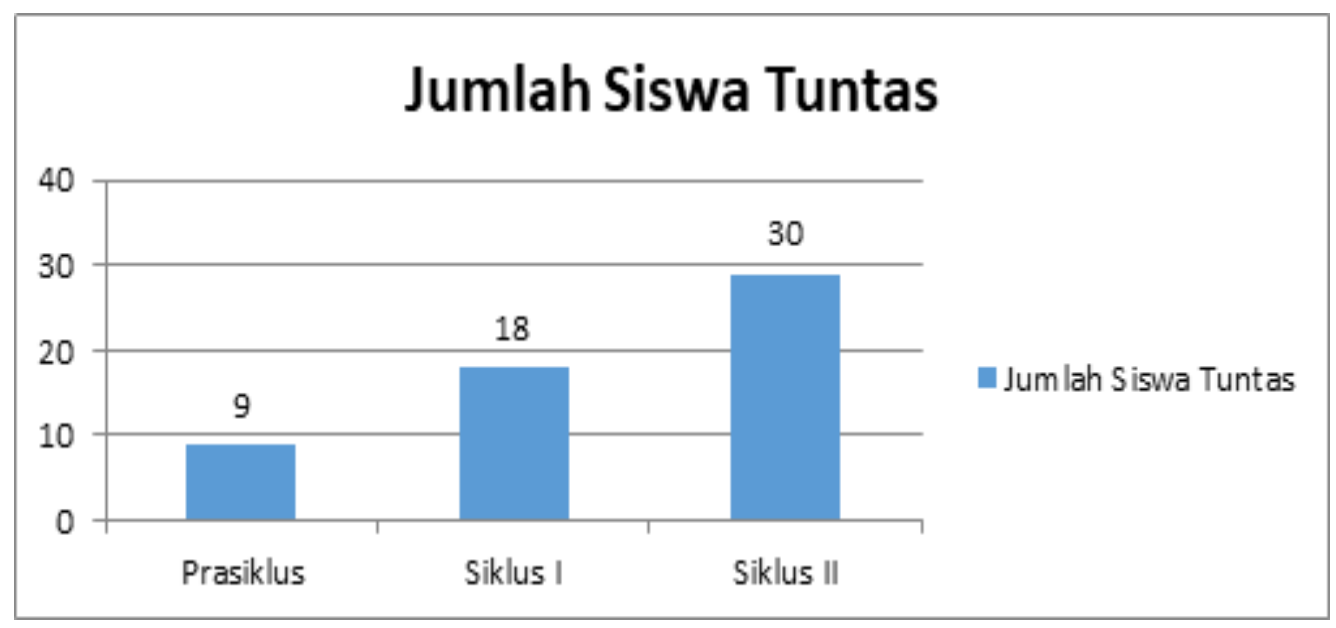

Gambar 2. Grafik jumlah siswa tuntas

Pada gambar 2. Bisa dilihat grafik jumlah siswa yang tuntas pada prasiklus sebesar 9 kemudian siklus I menjadi 18 dan siklus II bertambah menjadi 30. Sesuai dengan penelitian yang dilakukan oleh peneliti Aminoto dan Hairul Pathoni (2014) mengungkapkan bahwa penerapan media E-Learning berbasis Schoology dapat meningkatkan aktifitas dan hasil belajar fisika. Peningkatan hasil belajar siswa pada siklus I, dengan jumlah siswa yang tuntas sebanyak 14 orang dan pada siklus II jumlah siswa yang tuntas sebanyak 27 orang dari 32 siswa.

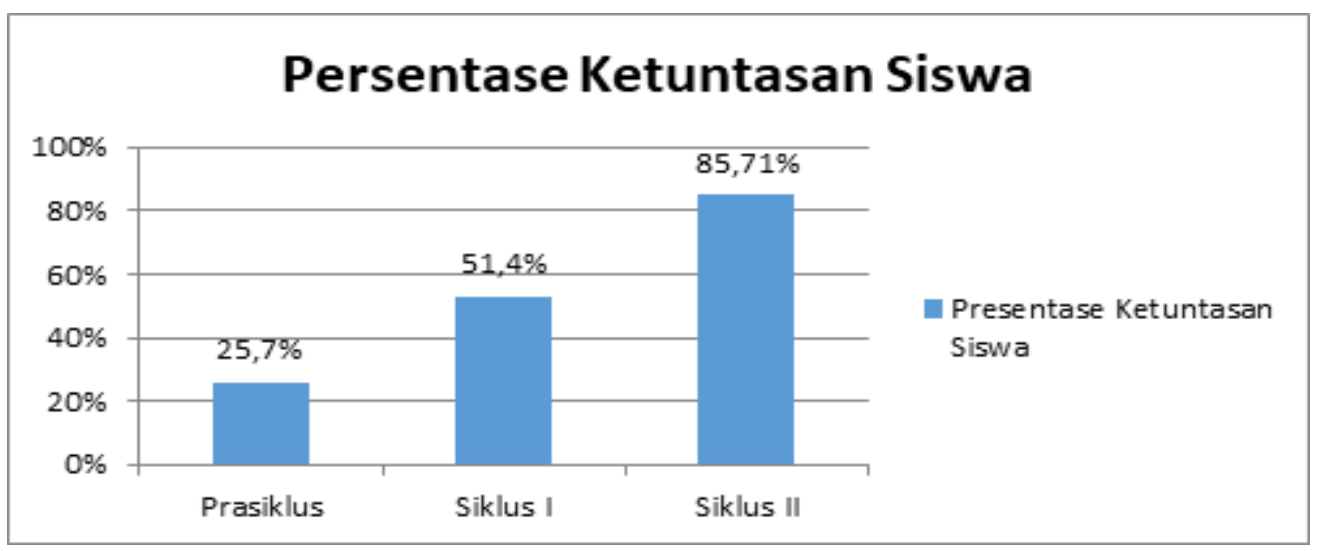

Gambar 3. Grafik persentase ketuntasan siswa

Pada grafik persentase ketuntasan siswa gambar 3. Bisa dilihat bahwa di prasiklus hanya $25,7 \%$ siswa yang tuntas, kemudian siklus I menjadi 51,4\% dan pada siklus II berubah menjadi $85,71 \%$. Sesuai dengan penelitian yang dilakukan oleh Hernani (2019) mengungkapkan bahwa model pembelajaran Blanded Learning Berbasis Schoology dapat meningkatkan nilai Biologi Peserta didik Kelas X4 IPA SMA N 4 Metro Semester Ganjil Tahun Pelajaran 2018/2019. Pada awal pra PTK peserta didik yang mencapai KKM atau peserta didik yang dikatakan tuntas sebanyak 56,25\% dan meningkat sebanyak $6,25 \%$ pada siklus I, yaitu sebesar 62,5\%. Dan meningkat lagi pada siklus II sebanyak 25\%\% peserta didik yang tuntas menjadi $87,5 \%$. 


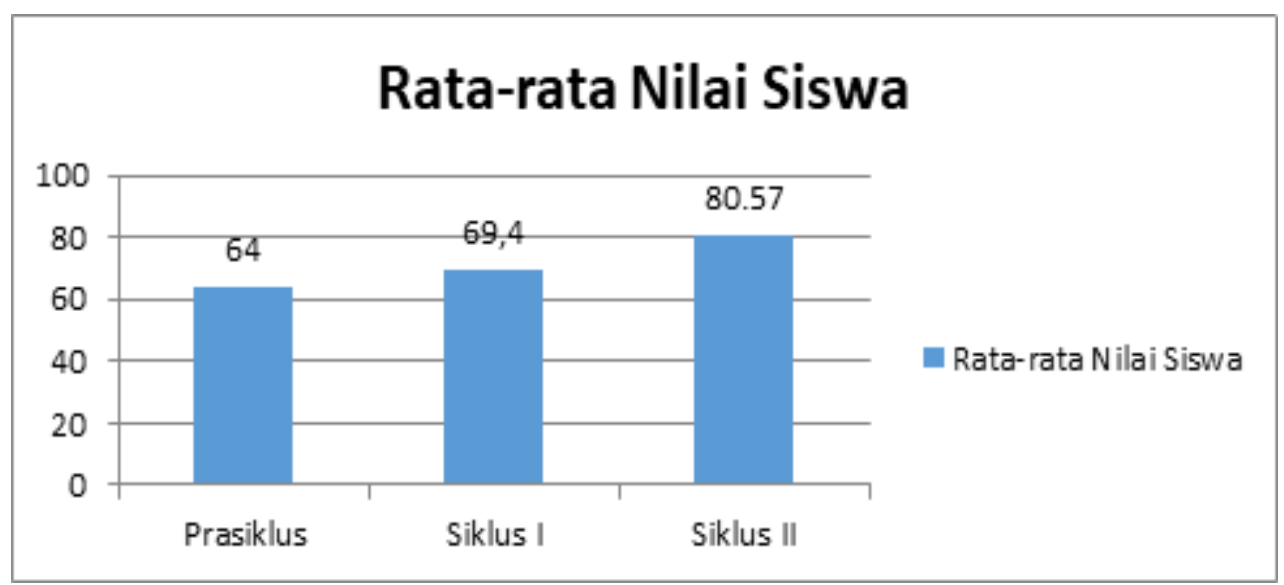

Gambar 4. Grafik rata-rata nilai siswa

Pada gambar 4. grafik diatas nilai rata-rata siswa tahap prasiklus hanya 64, kemudian pada siklus I meningkat menjadi 69,4 dan pada siklus II kembali meningkat menjadi 80,57. Sesuai dengan penelitian yang dilakukan oleh Wati dan Asnita (2016) mengungkapkan bahwa hasil evaluasi siswa kelas XII MIA5 SMAN 8 Pekanbaru, Riau dengan menerapkan pembelajaran E-Learning Schoology pada pelajaran biologi rata-rata nilai siklus I sebesar 84,5 mengalami kenaikan pada siklus II menjadi 88.

\section{KESIMPULAN}

Berdasarkan hasil penelitian yang sudah dilakukan, dapat disimpulkan bahwa :

Penelitian tindakan kelas dengan penerapan pembelajaran E-Learning Berbasis Schoology studi kasus yang dilakukan terbatas di lingkup SMAN 1 Karangdowo Kabupaten Klaten tepatnya di kelas XI IPS-4 yang berjumlah 35 siswa, telah berhasil meningkatkan hasil belajar siswa. Tingkat keberhasilannya dapat dilihat dari jumlah siswa yang tuntas, prosentase ketuntasan, dan rata-rata nilai siswa dari siklus I ke siklus II.

\section{SARAN}

Dari proses kegiatan belajar mengajar yang telah dilakukan peneliti, maka peneliti memberikan saran yang dapat digunakan pada penelitian selanjutnya dengan strategi pembelajaran Schoology. (1) Strategi pembelajaran Schoology dapat digunakan dalam pelajaran apapun termasuk pelajaran eksak. (2) Guru dapat menggunakan media pembelajaran E-Learning Schoology, agar pembelajarannya menjadi lebih bermakna dan menyenangkan

\section{DAFTAR PUSTAKA}

Adelia. (2014). adelia edukasi. Retrieved from www.adelia.web.id: http://www.adelia.web.id/contoh-ptk-penelitian-tindakan-kelas/

Aminoto, T. (2014). Penerapan Media E-Learning Berbasis Schoology untuk Meningkatkan Aktivitas dan Hasil Belajar Materi Usaha dan Energi di Kelas XI SMA N 10 Kota Jambi. Jurnal Sains dan Matematika Universitas Jambi.

Astrini et al. (2019). Pengaruh Model Pembelajaran Assurance Relevance Interest Assessment Satisfaction (ARIAS) Berbantuan E-Learning Schoology Terhadap Hasil Belajar TIK. International Journal of Natural Science and Engineering, 62-69.

Azizah. (2017). Pengaruh Penggunaan E-Learning dengan Schoology. Retrieved from AzizahPakultas Keguruan dan Ilmu Pendidikan: file:///C:/Users/WN10/Zotero/storage/LCGZJQQR/Azizah\%20- 
\%20FAKULTAS\%20KEGURUAN\%20DAN\%20ILMU\%20PENDIDIKAN\%20UNIV ERSITAS\%20.pdf

Fidiatun at al.,. (2018). Penerapan Blended Learning Berbasis Aplikasi Schoology Sebagai Upaya untuk Meningkatkan Hasil Belajar Administrasi Humas dan Keprotokolan. paedagogia Jurnal Penelitian Pendidikan.

Hernani at al.,. (2019). Peningkatan Nilai Kognitif Biologi Menggunakan Model Blanded Learning Berbasis Schoology Peserta Didik Kelas X4 IPA SMA N 4 Metro Tahun Pelajaran 2018/2019. BIOEDUKASI Jurnal Pendidikan Biologi e ISSN 2442-9805 Universitas Muhammadiyah Metro p ISSN 2086-4701.

Khafid et al.,. (2019). Optimalisasi Lingkungan Sekitar Sekolah Sebagai Alternatif Laboratorium IPA. Science Education and Application Journal (SEAJ). Vol. 1. No. 2: 74-83.

Kusumantara at al.,. (2017). Pengaruh E-Learning Schoology terhadap Hasil Belajar Simulasi Digital dengan Model Pembelajaran SAVI. Jurnal Pendidikan Teknologi dan Kejuruan Vol. 14, No. 2, Juli 2017, Hal :126 P-ISSN : 0216-3241 ; E-ISSN : 2541-0652, 126.

Madeamin, I. (2012). Model PTK (3): Model Spiral dari Kemmis \& Taggart. Retrieved from Ishaq Madeamin | BLOG: http://www.ishaqmadeamin.com/2012/11/model-ptk-3model-spiral-dari-kemmis.html

Michael. (2013). pengertian dan karakteristik E-Learning. http://scdc.binus.ac.id/himsisfo.

Murthosyiya. (2017). Penggunaan Schoology Sebagai Media Pembelajaran Sejarah Untuk Meningkatkan Hasil Belajar Siswa Kelas X Tab 3 Smkn 1 Singosari. repository.um.ac.id.

Rahmadianto, P. (2017). Pemanfaatan Schoology sebagai Media Pembelajaran dalam Meningkatkan Hasil Belajar Dasar Jaringan Pada Siswa Kelas X Multimedia SMK Negeri 3 Surabaya . Jurnal IT - Edu. Volume 01 Nomor 02 Tahun 2016, 82 - 87.

Rijal. (2017). manfaat E-Learning. Retrieved from https://www.rijal09.com/2017/04/9manfaat-E-Learning-dalam-pembelajaran.html

Safriana dan Marina. (2019). Capability Analysis of Pedagogical Content Knowledge (PCK) of Preservice Physics Teachers on Microteaching. Science Education and Application Journal (SEAJ). Vol. 1, No. 2:62-67. Retrieved from Science Education and Application Journal: http://jurnalpendidikan.unisla.ac.id/index.php/SEAJ

Septaria, K. (2019). Mengeksplorasi Argumentasi dan Pengetahuan Pendidik Ilmu Pengetahuan Alam (IPA) Tentang Pemanasan Global [Exploring the Arguments and Knowledge of Natural Sciences (IPA) Educators on Global Warming]. PEDAGOGIA: Jurnal Pendidikan, 8(2), 247-256.

Septiani at al.,. (2019). Pengembangan Instrumen Tes Literasi Sains Pisa Aspek Menjelaskan Fenomena ilmiah Kelas VII. Science Education and Application Journal (SEAJ). Vol. 1 No. 2: 46 - 55. Retrieved from . (2019). Pengembangan Instrumen Tes Literasi Sains Pisa Aspek Menjelaskan Fenomena Ilmiah Kelas VII. Science Education and Application Journal (SEAJ). .

Ulva at al. (2018). Penerapan E-Learning Dengan Media Schoology Untuk Meningkatkan Motivasi Dan Hasil Belajar Siswa Pada Kompetensi Dasar Mendeskripsikan Konsep Badan Usaha Dalam Perekonomian Indonesia. Jurnal Pendidikan Ekonomi: Jurnal Ilmiah Ilmu Pendidikan, Ilmu Ekonomi Dan Ilmu Sosial.

Utami et al. (2017). Pengaruh Penggunaan E-Learning dengan Schoology Materi Gravitasi Newton terhadap Hasil Belajar Siswa. Jurnal Pembelajaran Fisika. 